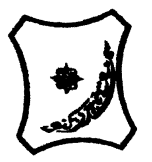

Bayero Journal of Pure and Applied Sciences: 10(1): 247 - 251

ISSN $2006-6996$

\title{
DETERMINATION OF CAFFEINE CONTENT IN SOME VARIETIES OF KOLA
} NUT (C. acuminate)

*Yalwa, I.R. and Bello, A.M.

Department of Chemistry, Sa'adatu Rimi College of Education, Kumbotso. P.M.B. 3218 KanoNigeria.

*Correspondence author:ibrahimr.yalwa@ymail.com; +2348038343900

\section{ABSTRACT}

The possibility of moisture, fat and caffeine contents of variety of kola nut (Cola acuminate) to differ with freshness and growing soil was tested. Varieties of kola nut'Sabo Dan Ikko', 'Daushe Dan Ikko', 'Sabo Dan Accra' and 'Daushe Dan Accra' were obtained from Mariri kola nut market ('Yangoro), Kano. The moisture content of the four varieties of kola nut, $C$. acuminate, were determined by drying the grated samples at $105^{\circ} \mathrm{Cfor} 48$ hours and the result was obtained as,30.58 $\pm 0.32,20.80 \pm 0.22,36.62 \pm 0.23$ and $25.16 \pm 0.31 \%$ for 'Sabo Dan Ikko', 'Daushe Dan Ikko', 'Sabo Dan Accra' and 'Daushe Dan Accra' respectively. The dried samples were defatted using the Soxhlet apparatus and petroleum ether of $60-80^{\circ} \mathrm{C}$ boiling point and the following fat contents were obtained, $2.53 \pm 0.25,2.80 \pm 0.03,2.61 \pm$ 0.35 and $2.72 \pm 0.22 \%$ for 'Sabo Dan Ikko', 'Daushe Dan Ikko', 'Sabo Dan Accra' and 'Daushe Dan Accra' respectively. The caffeine was extracted by the use of chloroform and the contents were found to be, $600 \mathrm{mg} / 20 \mathrm{~g}(3.00 \%), 580 \mathrm{mg} / 20 \mathrm{~g}(2.90 \%), 540 \mathrm{mg} / 20 \mathrm{~g}(2.70 \%)$ and $500 \mathrm{mg} / 20 \mathrm{~g}$ (2.50\%) for 'Sabo Dan Ikko', 'Daushe Dan Ikko', 'Sabo Dan Accra', 'Daushe Dan Accra' respectively. The results showed that generally the Lagos varieties contain more caffeine than the Accra ones.

Keywords: Kolanut, 'Daushe', 'Sabo', Caffeine, Kano

\section{INTRODUCTION}

Kola nut is a caffeine containing nut of ever green tree of the genus kola with primarily the species, Cola acuminate and cola nitida. Cola acuminate is an ever green tree of about 20 meters in height and has long ovoid leave pointed at both the end with a leathery texture. The trees have yellow flower with purple spot, and star shaped fruit with about a dozen round or square seeds which can be found in white seed shell. The tree is grown commercially around the world, particularly in Nigeria, Sri lanka, Indonesia, Brazil and other parts of South America. The tree is propagated through seed and, $C$. nitidaand $C$. acuminate can easily be interchange with other cola species. Kola nut is extremely popular amongst the inhabitant as a caffeine containing stimulant. The nut aroma is sweet and roselike. At first the taste is bitter but sweetens upon chewing. The nuts are eaten whole or powdered and mixed with liquid for a drink thus, sometimes used as flavoring ingredients in beverages (Kuoame and Scande, 2006).

The use of kola nut, like the coffee berry and tea leaf, appears to have ancient origin. It is chewed in many West African culture, individually or in social setting to restore vitality and ease hunger pangs. Kolanut is an important part of traditional spiritual practice of culture and religion in West Africa, particularly Nigeria (Somadhi, 2004). Kolanut is used as a religious object and scared offering during prayers, ancestors' venerations and significant life events such as naming ceremonies, weddings and funerals. It is also used in traditional divination system called Obi divination among the Igbo's. For this purpose kola nut divided in to four lobes is suitable. The nuts are cast upon a special wooden board and resulting patterns are read by a trained diviner. This ancient practice is currently enjoying increased growth within the United State and Caribbean. Kola nut is preferred among African Muslims who are forbidden to drink alcohol (Blades, 2000). Chewing kola nut can ease hunger pangs and is often used to treat whooping cough and asthma (Steinegger and Hansel, 1992). The caffeine present acts as a bronchodilator, expanding the bronchial air passages (Jayeola, 2001). However, frequent chewing of the kolanut can lead to stained teeth (Jarvis, 2002).

Various medicinal and pharmacological values have been observed in species of cola. Fresh kola nuts have stimulant action apart from the caffeine content, as they appear in European commerce. Their action is indistinguishable from that of other caffeine drugs (Jayeola, 2001). Caffeine in kola nut works by stimulating the central nervous system (CNS), heart and muscles (Ratsch, 2005). 
Medically, kola nut was found to have a marked stimulating effect on the human consciousness. In the short term, it may be used in nervous debility in states of weakness, aid in states of depression and may, in some people give rise to euphoric states, because of its caffeine content. Kolanut may relieve some migraine headaches. The phenolics and anthrocyanin are likely to provide antioxidant activity (Newall et al., 1996). Kolanut increases the capacity for physical exertion and for enduring fatigue without food; stimulating a weak heart, weakness, lack of emotion, depression, anxiety and sea sickness (Daels-Rakotoarisonet al., 2003). Kola nuts are also employed in the treatment of malaria fever (Odugbemi, 2006). Experiment using animals indicated, kolanut to have analeptic and tripolytic properties and stimulate the secretion of gastric juices (Grin, 2007). Traditionally the leaves, twigs, flowers, fruit follicles and the bark of cola nitida and cola acuminata are used to prepare a tonic as a remedy for dysentery, coughs, diarrhea, vomiting and chest complaints (Burkill, 1995).

Caffeine is solid with density $1.2 \mathrm{~g} / \mathrm{cm}^{3}$ and slightly soluble in water, but soluble in solvents like ethylacetate, chloroform, pyrimidine, pyrrolee.t.c. Caffeine is moderately soluble in alcohol and slightly soluble in petroleum ether, ether and benzene. It has a melting point of $273^{\circ} \mathrm{C}$ and a boiling point of $178^{\circ} \mathrm{C}$ (Sublimes). The most commonly used caffeine containing plants are coffee, tea, kola and to some extent cocoa. Caffeine is one of the world's most widely used drugs. Many anthropologists believe its use dated back to the Stone Age. Near the end of the $19^{\text {th }}$ century, cola products started to appear around the world and become one of the larger drank caffeine drinks (Jarvis and Martin, 1993).

Evidence of a risk to pregnancy is equivocal, but some authorities have concluded that prudent advice is for pregnant woman to limit consumption to the equivalent of two cups of coffee per day or less. Caffeine has diuretic properties when administered to people who are not used to it, but regular users develop a tolerance to this effect, and studies have generally failed to support the common notion that ordinary consumption contributes significantly to dehydration. With heavy use, strong tolerance develops rapidly and caffeine can produce clinically significant physical and mental dependence (Mayo clinic, 2012). Caffeine is toxic at sufficiently high doses. Ordinary consumption can have low health risks, even when carried on for years. There may be a modest protective effect against some diseases, including certain types of cancer. Caffeine can have both positive and negative effects on anxiety disorders. Some people experience sleep disruption if they consume caffeine, especially during the evening hours, but others show little disturbance and the effect of caffeine on sleep is highly variable, (Peters and Josef, 1967).

This research is aimed at determining and comparing the caffeine contents of the old and fresh kola nut(Cola acuminate) from the southern part of Nigeria referred to as 'Dan Ikko' meaning the Lagos variety, while kola nut from Ghana is the one referred to as 'Dan Accra'. Old kola nut is called 'Daushe' and the fresh is 'Sabo', while Lagos is called 'Ikko' all by the Hausas, who are known to be the major kola nut consumers in Nigeria. This can be referred to a saying thus, "kola nut, produced by the Yorubas, celebrated by the Igbos and eaten by the Hausas.'

\section{MATERIALS AND METHODS}

Four samples of Kola nut (C. acuminate) comprising of two Nigerian kola nuts, "Goro Sabo Dan Ikko" or Lagos fresh Kola and "GoroDaushe Dan Ikko" or Lagos old Kola and the other two being foreign, Ghana kola nuts, "Goro Sabo Dan Accra" or Accra fresh Kola and "GoroDaushe Dan Accra" or Accra old Kola were obtained and identified at Mariri Kola nut Market ('Yan goro'), Kano, Nigeria.

\section{Determination of Moisture and Fat Contents}

The four samples of kola nut were grated and driedin an oven at temperature of $105^{\circ} \mathrm{C}$ to obtain their moisture contents. They were then ground into fine powder and placed into an air tight container before further processes. The dried kola nut (C. acuminate) samples were defatted by using Soxhlet apparatus and petroleum ether of boiling point range of $60-80^{\circ} \mathrm{C}$ as the extraction solvent. $5.00 \mathrm{~g}$ of each dried sample in triplicate were defatted and the average calculated.

\section{Determination of Caffeine Content}

Caffeine content was determined according to Irgolic et al. (1982) methods. 20g of each of the dried and defatted kola nut samples was placed into a $250 \mathrm{ml}$ round bottom flask and $150 \mathrm{ml}$ de-ionised water was added to each. The mouth of each flask was connected to a refluxing system. Each of the flasks was placed into a heating mantle with a regulated temperature. As soon as the content begins to boil the tap of water was opened to allow draining the water out of the condenser and the sets were allowed to reflux for one hour. The refluxing system was turned off and allowed to cool for about thirty minutes. After cooling, the refluxed was sieved out of grated kola nut (with $0.1 \mathrm{~mm}$ and $0.2 \mathrm{~mm}$ sieve) into a $250 \mathrm{ml}$ beaker. 
The residues were discarded and the filtrate was retained and placed in ice block for 15 minutes. Then $150 \mathrm{ml}$ of the filtrate were placed into a $500 \mathrm{ml}$ separating funnel and $150 \mathrm{ml}$ of chloroform added gradually. The corked separating funnel was shaken until the chloroform, water interface was established. After two hours a clear solution was formed into which caffeine dissolved in chloroform. The caffeine chloroform solution was then transferred into a $250 \mathrm{ml}$ beaker and the chloroform evaporated over a water bath (Esther et al., 2005) leaving yellowish white caffeine crystals.

The crude caffeine obtained was purified by recrytallisation in toluene. In this $5 \mathrm{ml}$ of toluene was added onto the crude caffeine crystals in a $50 \mathrm{ml}$ beaker and heated on hotplate for the caffeine to dissolve. When

the crude caffeine dissolved, the beaker was removed from the hotplate, $10 \mathrm{ml}$ of petroleum ether $\left(60-90^{\circ} \mathrm{C}\right)$ was added and the caffeine allowed to crystallise (Okoliet al., 2012). The weight of the resultant pure caffeine crystals, now white was taken on a Mettlerelectric balance. The final product was confirmed as caffeine by thin layer chromatography (TLC) test and melting point determination.

\section{RESULTS AND DISCUSSION}

Moisture Content

The results obtained are as shown in Tables I, 2 and 3 below. Table 1 shows the mean moisture contents of the four varieties of kola nut ( $C$. acuminate).

Table 1: Mean Moisture Contents of the Kola nut (C. acuminate) Samples

\begin{tabular}{ccc}
\hline S/N & KOLANUT SAMPLE & MEAN MOISTURE CONTENT (\%) \\
\hline 1 & Sabo Dan Ikko (SDI) & $30.58 \pm 0.32$ \\
2 & Daushe Dan Ikko (DDI) & $20.80 \pm 0.22$ \\
3 & Sabo Dan Accra (SDA) & $36.62 \pm 0.23$ \\
4 & Daushe Dan Accra (DDA) & $25.16 \pm 0.31$
\end{tabular}

As shown in Table 1 above, the kolanut samples generally have high moisture contents. The results showed that 'Goro Dan Accra' (fresh and old) is having higher moisture content than its counterpart 'Goro Dan Ikko'. For both 'Goro Dan Ikko' and 'Goro Dan Accra', 'Goro Sabo' (fresh) has higher moisture content than 'GoroDaushe' (old). This is not surprising, because 'GoroDaushe' (old) was exposed for a longer period to air, therefore being dryer than 'Goro Sabo' (fresh) with shorter exposure. Fat Content Table 2: Mean Fat Contents of the Kola nut, $C$. acuminate Samples S/N KOLANUT SAMPLE

Sabo Dan Ikko (SDI)

Daushe Dan Ikko (DDI)

Sabo Dan Accra (SDA)

Daushe Dan Accra (DDA)
However, the moisture content of kolanut (fresh or old) generally depends on how it is taken care of in terms of exposure to air. This is why possibly the water contents of all the samples in this work are much lower than that of C. nitida obtained in Odebunmi et al, (2008) as $66.4 \%$, but very much higher than that of Dewole et al (2013), who reported the moisture content of both $C$. acuminate and $C$. nitida to be in the range of $9.73-9.81 \%$.

$\begin{array}{lcc}1 & \text { Sabo Dan Ikko (SDI) } & 2.53 \pm 0.25 \\ 2 & \text { Daushe Dan Ikko (DDI) } & 2.80 \pm 0.30 \\ 3 & \text { Sabo Dan Accra (SDA) } & 2.61 \pm 0.35 \\ 4 & \text { Daushe Dan Accra (DDA) } & 2.72 \pm 0.22\end{array}$

From Table 2 above, kola nut generally has low fat content and this result also shows that the old or "GoroDaushe" has higher content of the fat compared to fresh or "Goro Sabo" and "GoroDaushe Dan Ikko" has higher fat content that that of "GoroDaushe Dan Accra", while it is the other way round in the case of the fresh kola nut or "Goro Sabo". The fat content determined in this work is in line with Dewole (2013) finding that obtained a range of 2.20 $3.02 \%$. 
Caffeine Content

Table 3: Amount of Caffeine in the Kola nut, C. acuminate Samples

S/N KOLANUT SAMPLE MEAN CAFFEINE CONTENT (\%)

$\begin{array}{lcc}1 & \text { Sabo Dan Ikko (SDI) } & 3.00 \pm 0.12 \\ 2 & \text { Daushe Dan Ikko (DDI) } & 2.90 \pm 0.15 \\ 3 & \text { Sabo Dan Accra (SDA) } & 2.70 \pm 0.13 \\ 4 & \text { Daushe Dan Accra (DDA) } & 2.50 \pm 0.20\end{array}$

The mean caffeine content of the four different samples of Kola nut are as shown in Table 3 above. It can be observed from the results that varieties of kola nut have different caffeine contents as in Esther et al, (2005). As shown in Table 3, 'Goro Sabo Dan Ikko' contains averagely $600 \mathrm{mg}$ of caffeine per $20 \mathrm{~g}(3.00 \%)$, while 'Goro daushe Dan Ikko' has averagely 580mg per 20g (2.90\%). Again, 'Goro Sabo Dan Accra' contains averagely $540 \mathrm{mg}$ of caffeine per $20 \mathrm{~g}$ of kola nut (2.70\%), while 'Goro daushe Dan Accra' contains only an average of $500 \mathrm{mg}$ caffeine per $20 \mathrm{~g}$ of kola nut $(2.50 \%)$. This shows that 'Goro Sabo' (fresh) from both lkko (Nigeria) and Accra (Ghana) contain higher amount of caffeine than 'Gorodaushe' (old).

The results also showed that both 'Goro Sabo Dan Ikko'( fresh) and 'Goro Sabo Dan Accra' (fresh) varieties of kola nut used in this work have much higher average caffeine contents of 3.00 and $2.70 \%$ respectively compared to the those of Jayeola, (2001) with caffeine content of $1.50 \%$ for fresh kola nut, South, (2017), 1-1.5\%, BHF (2017), 1.5-2.0\%, while Lowrence (2014), estimated it as $2.0 \%$. AHS (2017), published the caffeine content of kola nut to be $2-3.5 \%$, which is in line with the results obtained in this work. However, Okoli et al (2012), obtained the caffeine in $\mathrm{K}$. acuminate as $4.7 \%$ which is much higher than even those of 'Goro Sabo Dan Ikko' and 'Goro Sabo Dan Accra' samples of this work.

From the results 'Goro Dan Ikko' (Nigeria), both Sabo (fresh) and 'Daushe' (old) have higher percentage of caffeine compared to the 'Goro Dan Accra' (Ghana), both Sabo

\section{REFERENCES}

Aheme, S.A.; Jiwan, M.A.; Daly, T. and O'Brien, N.M. (2009). Geographical Location Has Greater Impact on Carotenoid Content and Bioaccessibility from Tomatoes than Variety. Plant Food Human Nutrition 64(4): 250-256.

Amicus Herbs and Superfoods, (AHS), (2017). Kola nut. www.healthyherbaltea.nl accessed 18/02/2017 (fresh) and Daushe (old). The differences in caffeine contents may be due to climatic factors and edaphic factor of the kola nut (Aheme et al., 2009). According to these authors, these factors can cause serious variation in nutritional properties of the kola nut, which therefore includes the caffeine content.

\section{CONCLUSION}

From the results, 'Goro Sabo' (fresh) has higher moisture content than 'Goro Daushe' (old) for both 'Goro Dan Ikko' (Nigeria) and 'Goro Dan Accra' (Ghana), although the difference is not all that much. However, there is much difference between the values determined in this work and others; some much higher and much lower for some. This shows that moisture content of kola nut in general depends on, freshness, the nature of storage or exposure to air.

The fat content of kola nut, $C$. acuminate is generally very low and averagely similar for all the four varieties as compared to other nuts like ground nut with much higher content. The experimental results have shown that the caffeine content in different kola nut varies. It was found that 'Goro Dan Ikko' (Nigeria), both fresh and old, has higher caffeine content compared to its counterpart 'Goro Dan Accra' (Ghana), both fresh and old. It can also be concluded from this work that kola nut contains caffeine as $2.5-3.0 \%$ of its dry matter. The caffeine content of kola nut can also differ with difference in the soil it is grown in, climatic and adaphic factors.

Baseline of Health Foundation, (BHF), (2017). Kola nut (cola acuminate): Health Benefits of Kalonut. www.baselinenutritionals.com accessed 17/02/2017

Blades, M. (2000). Functional foods or Neutraceutics. Nutrition and food science. 30 (2):73-75. 
Burkill, H.M. (1995). The Useful Plant of Tropical West Africa. Vol. 11. $2^{\text {nd }}$ Edition.

Daels-Rakotoarison D.A; Kouakoua, G; Bailleu, F; Trotin, F. (2003). "Effects of a caffeine- free cola nitida nut extract on elestase/ alpha -1- proteinase inhibitor balance". Journal of Ethnopharmacol 89(1):143-150.

Dewole, E.A.; Dewumi, D.F.A.;Alabi, J.Y.T. and Adegoke, A.(2013). Proximate and Phytochemical of Cola nitida and Cola acuminata. Pakistan Journal of Biological Sciences, 16: 1593-1596.

Lowrence, E. (2014). Cola. Encyclopedia Americana. Grolier (online)

Esther, W; Petu-Ibikunle, A.M; Audu, A; and Shallagwal, Y.Y. (2005). "Assessment of damage and losses to kola nut caused by kola nuts weevils BalanogasticsKolae (Desbr) coleoptera: Curculionidae". Department of Agricultural Engineering, Ramat polytechnic MaiduguriNigeria. www.Asopah.org/.../ajgab/0/09148.pdf

Grin, A. (2007). Germplasmesources information Network. Belts Ville, Maryland. www.grin-global .org Accessed 25/03/2013.

Jarvis, M. (1993). "Does caffeine intake enhance absolute level of cognitive performance? Psychopharmology 110 $(1-2): 45-52$.

Jayeola, O.C . (2001). "Preliminary studies on the use of kola nut (Cola nitida) for soft drink production". Journal of Food Technology in Africa. 6 (1): 25-26.

Kuome, C; Sacande, M. (2006). Kola nitida (vent). Schott and Endl. Seed leaflet vol.111.
Mayo Clinic Staff (MCS) (2012). “Pregnancy nutrition: foods to avoid during pregnancy". Mayo clinc. www.mayoclinic.com/ healthinformation. Accessed 2012-04-15

Newall, C.A; Anderson, L.A; and phillipson, J.D. (1996). Herbal medicines: A guide for health professionals London: The Pharmaceutical Press; page 84.

Odugbemi, T. (2006). Outlines and pictures of medicinal plants from Nigeria. Vol.10.University of Lagos press; page 158.

Okoli, B.J.; Abdullahi, K.; Myana, O. and Iwu, G. (2012). Caffeine Content of Three Nigerian Cola. Journal of Emerging Trends in Engineering and Applied Sciences. 3(5): 830-833

Peters, J.M. and Josef A. (1967). Toxicity of caffeine. "The journal of clinical pharmacology 7:131-141.

Ratsch, C. (2005). The Encyclopedia of psychoactive plants:Ethnopharmacology and its applications. $2^{\text {nd }}$ edition. Foreword Publisher. Pp 325-327.

Somadhi, A.A. (2004). Practitioners Hand Book forthelFA Professional. IleOrunmila Communications. p1

South, C. (2017). Clayton's Health Facts: Kola nut. www.bodybuilding.com accessed $18 / 02 / 2017$

Steinegger, E and Hansel, R. (1992). BerlinHeidelberg: $\quad$ springer verlag; pharmakognosie. $5^{\text {th }}$ edition. 